\title{
Clinical Experience of Open-heart Surgery by Means of Hypothermia and Heart-lung Machine
}

\author{
By \\ Togo Horiuchi, Kei Koyamada, Takeo Honda, \\ Takeshi Ishitoya, Yasuhiko Sagawa, Mitsuoki \\ Matsumura, Toshio Tsuda, Shigehiro \\ Ishikawa, Eiji Ishizawa, Yutaka \\ Saito and Toshiro Matsumoto \\ From the Second Department of Surgery, Tohoku \\ University School of Medicine, Sendai; \\ Director: Prof. $M$. K a s a $i$
}

(Received for publication, March 30, 1964)

\begin{abstract}
A total of 216 cases underwent open-cardiac operations up to December 1963. The hypothermia was applied for 121 instances, while 95 individuals were operated upon by means of heart-lung machine. On the basis of the above clinical experiences, advantages and disadvantages of hypothermia and heart-lung machine have been described and our current point of view about operative indications has been presented. Furthermore, detailed account has been made on history and development of hypothermia and heart-lung machine for open-heart surgery in our department. Some improved points which may contribute to widening indications of hypothermia, in particular, have been discussed.
\end{abstract}

\section{INTRODUCTION}

A total of 216 patients underwent open-heart operations in our surgical department by December 1963. The cases in whom hypothermia was applied with surface-cooling method numbered 121. Ninety-five cases have been operated upon by means of artificial heart-lung machine. Patients operated upon under hypothermia almost equal to those under heart-lung machine in terms of the number of cases. Under these circumstances, it seems to be pertinent for us to examine advantages and disadvantages of the use of hypothermia and heartlung machine. History of open-cardiac operations in our surgical department will be briefly reviewed. Discussions are to be done on operative results and indications for application of hypothermia and cardiopulmonary-bypass procedure.

堀内藤吾, 小山田惠, 本田健夫, 石戸谷武, 佐川安彦, 松村光起, 津田敏夫, 石川茂弘, 石沢栄次, 意藤 裕, 松本俊郎 
History of open-heart operations in our surgical department

Hypothermia with the use of surface-cooling method was pioneered by Swan, Lewis and Bigelow. With emergence of this genuine concept, the method was first put into clinical application in 1953 as a means of open-cardiac operation. The heart-lung machine which was devised by Gibbon had been extensively investigated and improved by Lillehei, Kirklin and others in 1954 to the point where its use has been widely accepted as one of the important means of opencardiac surgery. Since that time, most of cardiac surgeons have tended to use heart-lung machine. In Japan open-heart operations have been initially tried under light hypothermia. At temperature below $30^{\circ} \mathrm{C}$, particularly $28^{\circ} \mathrm{C}$, however, ventricular fibrillation tends to occur. In addition, circulatory interruption for more than 10 minutes has been hardly attained ${ }^{1,2)}$. Because of these disadvantages, its use was abandoned. Since 1956, it has been seemingly replaced by heart-lung apparatus. About this time Watanabe and Okamura in our department devoted themselves to experimental investigation of hypothermia with surface-cooling method. They succeeded in resuscitation of the heart in a dog under hypothermia of $12^{\circ} \mathrm{C}$ of the rectal temperature after circulatory occlusion of 2 hours and 40 minutes' duration ${ }^{3}$. It has been proved by a number of experiments that ventricular fibrillation does not occur during the cooling process when the animal is deeply anesthetized with ether. Furthermore, the maximum permissible occlusion time was found to be 30 minutes at $25^{\circ} \mathrm{C}, 1$ hour at $20^{\circ} \mathrm{C}$ and 2 hours at $15^{\circ} \mathrm{C}$ of rectal temperature. These experimental works have been presented to the 1958 Annual Congress of German Surgical Association by Ishikawa and Okamura. Since that time, this method of hypothermia has been introduced as "Japanische Methode" 4,5$)$, which prompted reappraisal of the current method of deep hypothermia. On the basis of the above experiments, the method has been transferred to clinical application in order to achieve circulatory interruption of 20 minutes' duration at $25^{\circ} \mathrm{C}$, provided that resuscitation of the heart is easy after release of the occlusion and the interruption is within a range of safety. In June 1958, radical operation for atrial septal defect in a 10-year-old girl complicated by cardiac failure was first attempted with success. Since then, the method of hypothermia has been applied mainly for radical operations of atrial septal defect and pulmonary stenosis. It was found, however, that restoration of normal cardiac rhythm was difficult in cases where strong cardiac action failed to follow within 25 minutes from the beginning of circulatory interruption at $25^{\circ} \mathrm{C}$. Furthermore, in severe cases circulatory interruption of even a short duration caused irreversible changes in the myocard. For the purpose of accomplishing open-heart operations with safety which would require a longer period of time, heart-lung machine has been adopted since 1960. In an early period, the heart-lung apparatus had been utilized for radical 
operation of ventricular septal defect, but later for surgical correction of more complicated cardiac diseases. Since this sort of heart-lung machine is not suitable for use in infants, hypothermia has been applied with some modifications for radical operation of ventricular septal defect in the infantile period since 19616).

\section{OPERATIVE TECHNIQUE}

In this section, the method of hypothermia currently in use and that of the use of Gibbon's heart-lung machine (Mark G-K) are to be described. Then, the detailed operative techniques on the repair of atrial septal defect, ventricular septal defect, pulmonary stenosis, tetralogy of Fallot and their accompanied anomalies are to be described, since majority of cardiac anomalies seen in our group of patients are related to the above mentioned.

1) Hypothermia with surface-cooling method. After deep anesthesia with ether (the third stage, plane 3), the patient was placed in ice-water tub or aircooling chamber. When the temperature reached around $28^{\circ} \mathrm{C}$ by rectum, the patient was elevated and placed on the operating table. Because of the afterdrop phenomena, the body temperature decreased down to approximately $25^{\circ} \mathrm{C}$. At this temperature, open-heart operations have been carried out. After completion of operation, a certain period of time was awaited until effective cardiac pulsation was resumed when the chest could be closed. The rewarming was initiated by placing the patient in warm-water tub $\left(43^{\circ} \mathrm{C}\right)$ or air-warming chamber. At $35^{\circ} \mathrm{C}$ the patient was transferred to the bed.

2) Extracorporeal circulation by means of heart-lung apparatus. Venous blood was drawn by hydrostatic energy through the cannula inserted into the superior and inferior venae cavae via the right auricle. Oxygenation of blood was performed in the screen-type heart-lung machine. The oxygenated blood was reinjected into the cannula inserted into the femoral artery at the flow rate of 70 to $80 \mathrm{cc} . / \mathrm{min} . / \mathrm{kg}$. of body weight. Partial perfusion was not done at the beginning of the interruption and release of the clamps. In case marked collateral circulation from the bronchial arteries was noted, blood was drawn from the left auricle as well, which was put back into the circuit of the heart-lung machine. Cardiac arrest was obtained by anoxia or injection of Young's solution into the coronary arteries. No active hypothermia was added to the extracorporeal circulation. Transfusion of the preserved cold blood usually induced the lowering of body temperature down to about $32^{\circ} \mathrm{C}$. Resumption of normal body temperature was obtained with rewarming blanket by the time of completion of operation.

3) Atrial septal defect. The chest was opened by the right thoracotomy incision made at the 4 th intercostal space. The sternum was transected. In hypothermia, the superior and inferior venae cavae were occluded with tapes. Aorta and pulmonary artery were clamped altogether after awaiting several 


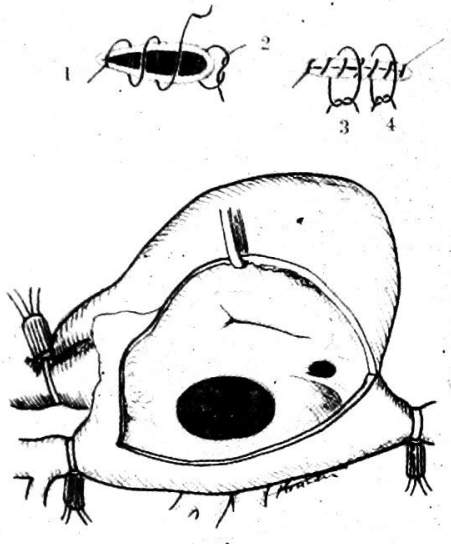

A
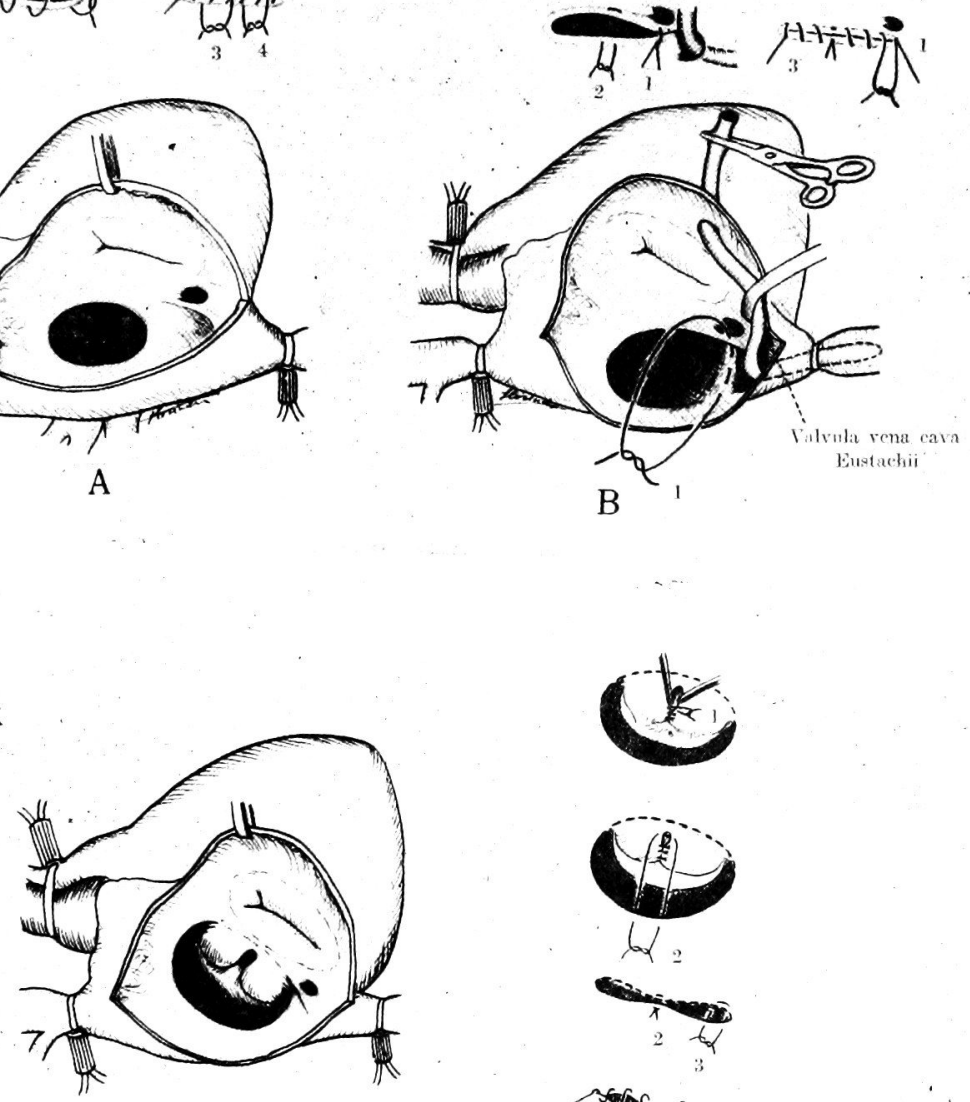

2 6o

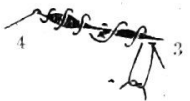

C

...

Fig. 1. Method of repair of atrial septal defect under hypothermia.

A: Method of closure of ostium secundum defect (central defect).

B: Method of closure of ostium secundum defect (lower defect). In ordinary method of closure of the defect, abnormal drainage may be inadvertently obtained, namely, inferior vena cava may enter the left auricle. When hypothermia is applied, in order to identify the inferior vena cava, a French catheter is inserted into it beforehand. The lower margin of the defect is first sutured as in the diagram and later closure is completed just as in Fig. A.

C: Method of closure of ostium primum defect with associated cleft of mitral valve. 
pulsatile flows following injection of $2 \mathrm{mg}$. of heparin into the right auricle. The right auricle was then incised. The defect was closed with running over-and-over stitches and 3 additional interrupted sutures (Fig. 1-A,B,C). Air bubbles within the auricle were evacuated by filling the space with heparinized blood. The incisional wound of the auricle was closed and all the clamps removed. In general, cardiac rhythm was resumed and became active spontaneously. When the cardiac action was not strong enough, the electric pacemaker was employed. The use of cardiopulmonary bypass procedure presents no particular problem in this respect.

4) Ventricular septal defect. The heart was usually exposed by the midsternal splitting incision. Location of the defect was first examined by palpating a thrill present over the surface of the heart. The incision of the right ventricular wall was made over that region. In the early days of experiences, vertical incision was performed over the right ventricle, but recently transverse incision has been preferred. The closure of the defect was done with direct sutures or Teflon pledgets. For a large defect, a Teflon patch was applied with continuous suturing technique (Fig. 2).

Although no particular comment would be necessary for heart-lung machine, in hypothermia, in order to prevent intracardiac coagulation, $2 \mathrm{mg}$. of heparin were injected into the right auricle after clamping of the superior and inferior venae

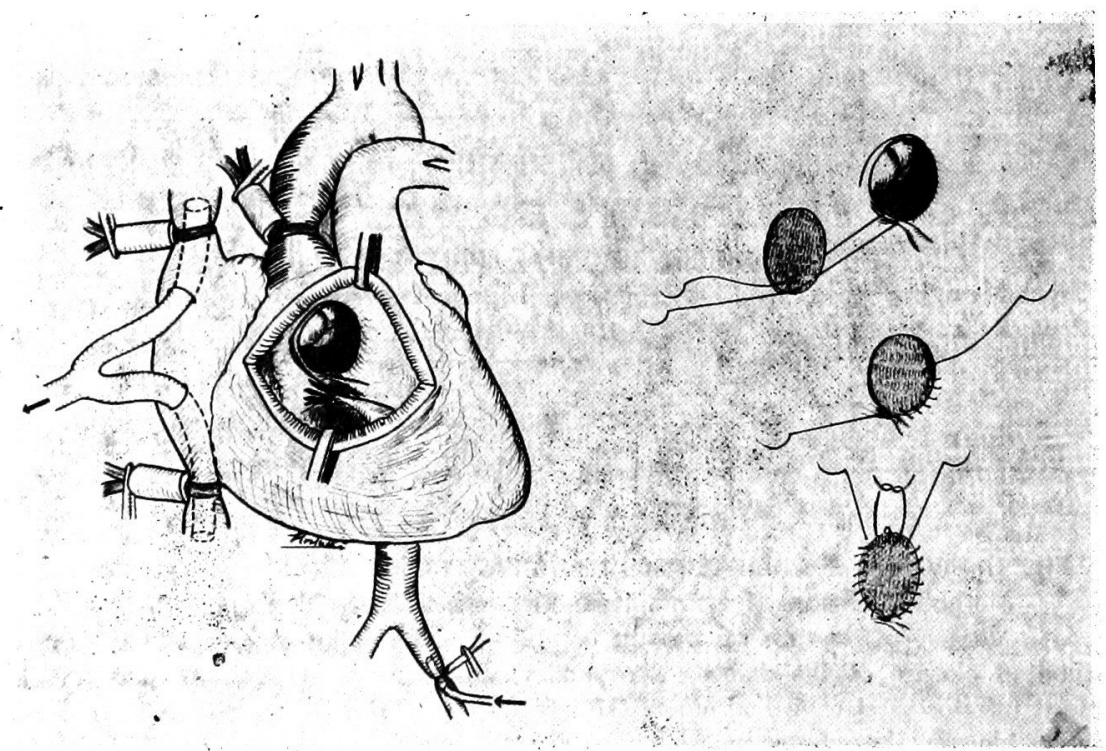

Fig. 2. Method of repair of ventricular septal defect with associated pulmonary hypertension by means of heart-lung machine. A transverse incision is made on the right ventricular wall and the defect closed by continuous suturing of a Teflon patch. 
cavae. At the time when the incision of the right ventricular wall began to be approximated after closure of the defect, heparinized oxygenated blood was pumped into the aorta via a needle previously indwelled in the aorta, thus establishing coronary perfusion. Thereby intense cardiac action could be restored spontaneously. When one could predict prolongation of operation because of a large defect, cardiac arrect was artificially induced with Young's solution. When the cardiac action was not strong enough, the application of the electric pacemaker or administration of $0.3 \mathrm{cc}$. of noradrenaline in $0.1 \%$ solution and $10 \mathrm{cc}$. of $0.5 \%$ calcium chloride could be considered. For associated patent ductus arteriosus, ligation of the duct was first performed, which was followed by the repair of ventricular septal defect.

5) Pulmonary stenosis. In principle, the heart was reached by the midsternal splitting incision or left thoracotomy at the 4th intercostal space with added transection of the sternum. When an uncomplicated valvular pulmonary stenosis was detected, pulmonary trunk was incised and valve exposed. Incision was made on the valve adequately so that the valve might become bicuspid. When narrowness of the pulmonary trunk inhibited adequate exposure or concommitant presence of intracardiac anomalies could be suspected, the right ventricular conus was incised, thus exposing the valve.

For pulmonary stenosis with associated atrial septal defect, the heart was exposed by the midsternal splitting incision or bilateral thoracotomies. Surgical correction of the pulmonary stenosis followed closure of the atrial septal defect.

6) Tetralogy of Fallot. Heart-lung machine was used in all instances because of prolonged operation. The heart was reached by the midsternal splitting incision. The right ventricular wall was incised longitudinally or transversely and stenosis of the pulmonary conus sufficiently excised. The ventricular septal defect was then closed with continuous sutures of a Teflon patch. In an attempt to enlarge the outflow tract of the right ventricle, duplicated spindle-shaped Teflon patch was sutured over the right ventricle when an occasion arose.

\section{OPERATIVE RESULTS}

1) Atrial septal defect. Cases with more than $30 \%$ left to right shunt-ratio were operated upon for selective closure of atrial septal defect by using mainly hypothermic anesthesia, while those with more than $40 \mathrm{~mm} \mathrm{Hg}$ of pulmonary arterial pressure by systole whose clincial symptoms were considered relatively severe were subjected to the use of heart-lung machine. A total of 66 cases were operated upon for atrial septal defects. The ages ranged from 3 to 32 years. This series included 7 individuals who were complicated by partial anomalous pulmonary venous return, ventricular septal defect, persistent left superior vena cava and light degree of Ebstein's disease. Three cases with total anomalous 
TABLE I. Atrial Septal Defect-A Total of 66 Cases

(up to Dec. 1963)

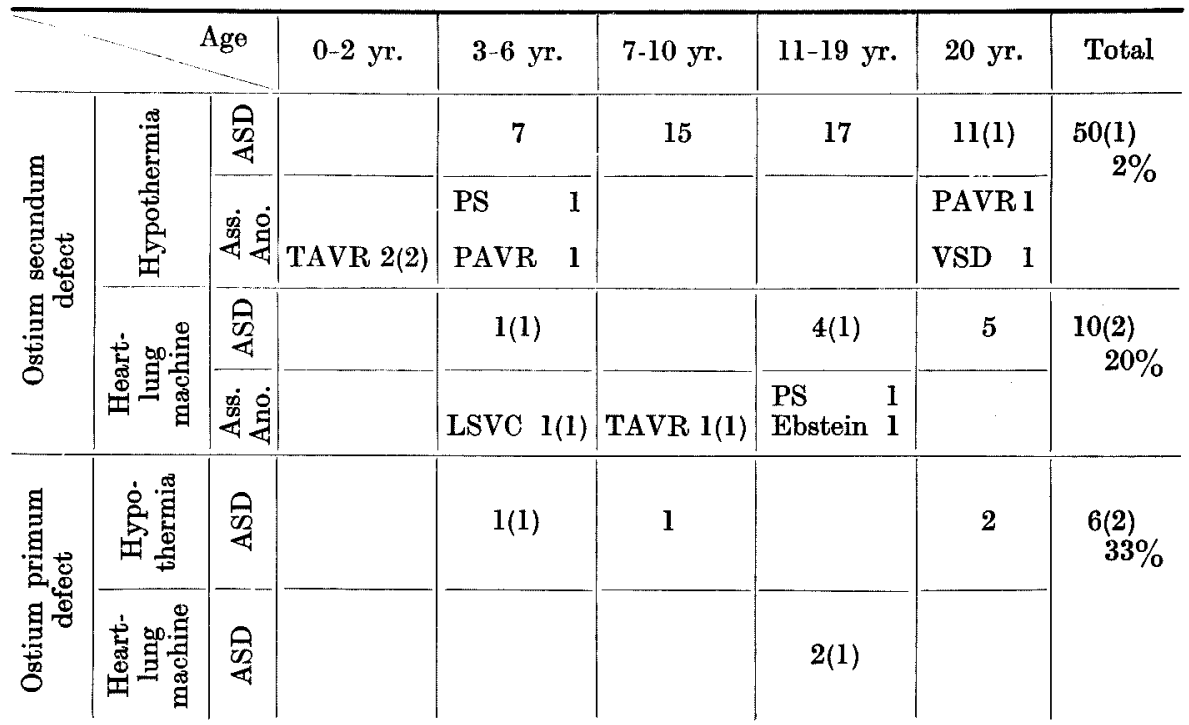

Abbreviations for all tables: yr., years; Ass. Ano., associated anomaly; ASD, atrial septal defect; TAVR, total anomalous pulmonary venous return; PAVR, partial anomalous pulmonary venous return; PS, pulmonary stenosis; VSD, ventricular septal defect; LSVC, persistent left superior vena cava; Ebstein, Ebstein's anomaly; PDA, patent ductus arteriosus; LV-RA, left ventricle-right atrial communciation with tricuspid insufficiency; BSD, bulbar septal defect; Valsalva, ruptured aneurysm of the sinus of Valsalva; Inf. S., infundibular stenosis: C. Trans., corrected transposition; T/F, tetralogy of Fallot; D. card., dextrocardia.

( ), number of death.

pulmonary venous return were, however, excluded from the present series (Table I). Fifty patients were operated upon for ostium secundum defect, among whom only one died after operation (mortality rate: $2 \%$ ). This single instance was operated in the early days of experience, where open-heart operation was done without noticing the abnormally low location of the right subclavian vein when the superior vena cava was occluded, resulting in blood loss of a large amount. Consciousness of the patient was not resumed following operation, subsequently dying 12 hours postoperatively. Among the 49 survivors, 2 cases had associated anomaly of the right pulmonary vein, namely draining into the superior vena cava, which were successfully operated under hypothermia (Fig. 3). For 10 cases with ostium secundum defect, heart-lung machine was utilized. Two of them died. One of the 2 cases had pulmonary hypertension, dying from pulmonary edema 50 hours after reoperation. The other one succumbed from shock secondary to loss of blood without noticing persistent left superior vena cava, which caused 


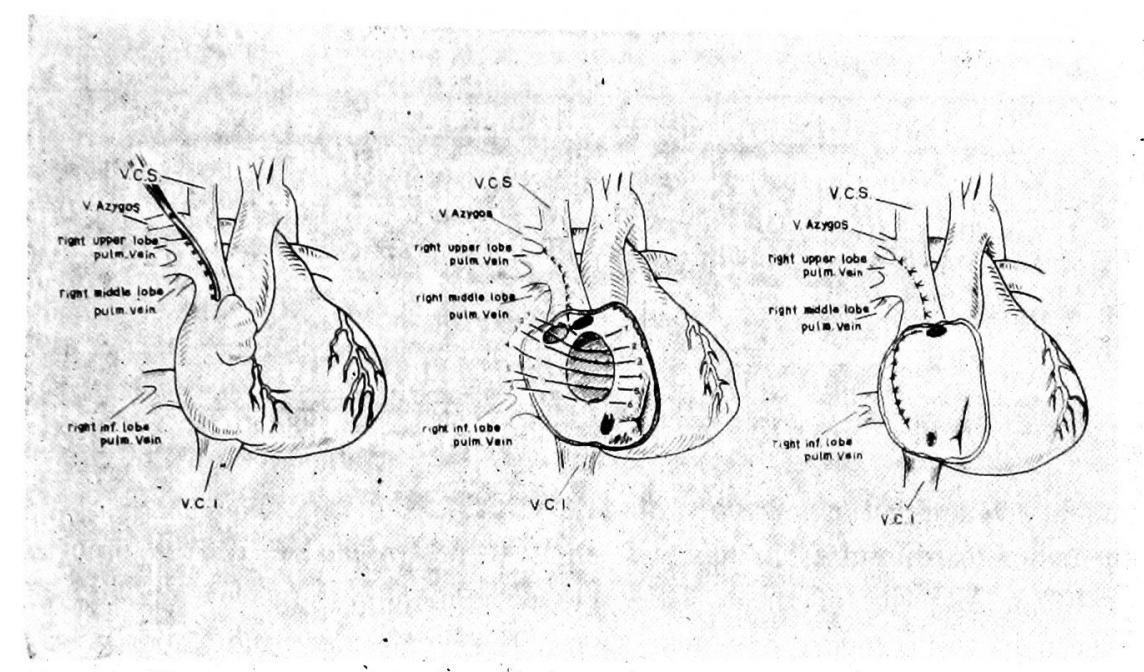

Fig. 3. Method of repair of atrial septal defect with associated partial anomalous pulmonary venous return into superior vena cava under hypothermia.

Before transferring the procedure to open heart, as shown in the diagram, a vascular clamp is applied over the center of superior vena cava and division is first completed with sureness by applying several mattress sutures along the clamp. Thereafter, the heart is opened and repair of atrial septal defect completed. At the same time, correction is made of the anomalous pulmonary vein in such a fashion that the pulmonary vein may drain into the left auricle.

unbalance in the exptracorporeal circulation. A total of 6 cases with ostium primum defect were operated. Hypothermia was applied for 4 of 6 , while heartlung machine employed for the other 2 . One patient died in each group. The one subjected to hypothermia could not restore cardiac action despite circulatory interruption of a short duration, namely, 7 and half minutes at $24.5^{\circ} \mathrm{C}$. This certainly makes one reconsider the limitation of application of hypothermia for such severe atrial septal defects. One death in the group of heart-lung machine was due to postoperative hemorrhagic tendency.

2) Ventricular septal defect. In principle, operative indication of the ventricular septal defect was limited to the patients with more than $20 \%$ left to right shunt-ratio. The heart-lung machine was mainly utilized. For infantile cases in whom the application of the heart-lung machine was difficult, hypothermia was adopted. Recently, however, hypothermia has been also applied for children of older age group with mild degree of the disease. A total of 114 patients were operated upon for ventricular septal defect, whose ages varied from 3 months to 35 years. The series included 12 cases with associated anomalies such as patent ductus arteriosus, ruptured aneurysm of the sinus of Valsalva, bulbar septal defect?), left ventricular right atrial communication, partial anomalous 
TABLE II. Ventricular Septal Defect-A Total of 114 Cases

(up to Dec. 1963)

\begin{tabular}{|c|c|c|c|c|c|c|c|c|}
\hline \multicolumn{2}{|c|}{ Age } & $0 \mathrm{yr}$. & $1-2 \mathrm{yr}$. & 3-6 yr. & 7-10 yr. & 11-19 yr. & $20 \mathrm{yr}$. & Total \\
\hline \multirow{2}{*}{ 家密 } & VSD & $26(6)$ & $16(4)$ & 7 & $8(1)$ & & & \multirow{2}{*}{$\begin{array}{l}57(11) \\
20 \%\end{array}$} \\
\hline & $\begin{array}{l}\text { Ass. } \\
\text { Ano. }\end{array}$ & $\begin{array}{l}\text { PDA 2 (1) } \\
\text { PAVR 1 }\end{array}$ & LSVC 1 & $\begin{array}{ll}\text { PDA } & 1 \\
\text { LV-RA } & 1\end{array}$ & PDA 1 & & & \\
\hline \multirow{2}{*}{ 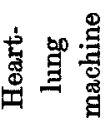 } & VSD & & & 10 & $20(4)$ & $24(1)$ & $3(1)$ & \multirow{2}{*}{$\begin{array}{r}57(6) \\
10 \%\end{array}$} \\
\hline & $\begin{array}{l}\text { Ass. } \\
\text { Ano. }\end{array}$ & & & & $\begin{array}{ll}\text { PDA } & 1 \\
\text { LV-RA } & 1\end{array}$ & $\begin{array}{ll}\text { BSD } & 1 \\
\text { Valsalva } & 1\end{array}$ & Valsalva 2 & \\
\hline
\end{tabular}

pulmonary venous return, etc. (Table II). Fifty-seven individuals were operated upon under cardiopulmonary-bypass with 6 postoperative deaths (mortality rate: $10 \%$ ). Majority of the 6 patients had pulmonary hypertension and could be placed in the category of severe cases. The deaths were due to postoperative right heart failure in 3 , bleeding tendency in 1 , and brain damage in 1 . Those operated upon exclusively under hypothermia were usually less than 3 years old, numbering 57. Eleven of them died (mortality: 20\%), most of whom had been severely ill with complicated associated anomalies. The causes of deaths were inability of cardiac resuscitation after open-heart operation or hypotension in 5, respiratory insufficiency in 3, right heart failure in 2 and atrial-ventricular block in 1. Patent ductus arteriosus was encountered in 3 instances among the survivors of the hypothermic group, which was simultaneously corrected by the midsternal splitting incision. There was one case with associated partial anomalous pulmonary venous return. Since it was considered that the ventricular septal defect was the one which would be a menace to this individual's life, only ventricular septal defect was radically operated upon with marked relief of the symptoms. Table III illustrates the relationship between the systolic pressure of the pulmonary artery which is indicative of the severity of ventricular septal defect and mortality rate. The operative results of those with pulmonary hypertension were found to be poor. The right heart failure was a main cause of

TABLE III. Systolic Pulmonary Pressure and Operative Mortality in Ventricular Septal Defect

\begin{tabular}{l|c|c|c|c|c}
\hline $\begin{array}{c}\text { Systolic pulm. } \\
\text { pressure mm Hg }\end{array}$ & $\begin{array}{l}\text { Below } \\
\mathbf{4 0 m m} \mathrm{Hg}\end{array}$ & $\begin{array}{r}40-59 \mathrm{~mm} \\
\mathrm{Hg}\end{array}$ & $\begin{array}{r}60-79 \mathrm{~mm} \\
\mathrm{Hg}\end{array}$ & $\begin{array}{l}\text { Above } \\
80 \mathrm{~mm} \mathrm{Hg}\end{array}$ & Total \\
\hline $\begin{array}{l}\text { Number of } \\
\text { operated cases }\end{array}$ & $\mathbf{7 7}$ & 19 & 7 & 11 & 114 \\
\hline Number of death & $\begin{array}{l}7 \\
9 \%\end{array}$ & $\begin{array}{c}3 \\
16 \%\end{array}$ & $\begin{array}{c}3 \\
43 \%\end{array}$ & $\begin{array}{c}4 \\
36 \%\end{array}$ & $\begin{array}{l}17 \\
15 \%\end{array}$
\end{tabular}


death among children of older age in the group of heart-lung machine. On the other hand, respiratory insufficiency was the most important among infants in the hypothermic group.

3) Pulmonary stenosis. Indications were limited to the patients with more than $50 \mathrm{~mm} \mathrm{Hg}$ pressure gradient between systolic pressure of the right ventricle and that of the pulmonary artery. In the early period, heart-lung apparatus was used for the repair, but hypothermia in the later period. Recently, valvulotomy with closed technique has been frequently employed via transventricular approach with the use of Brock's valvulotome. A total of 14 individuals underwent surgical correction of pulmonary stenosis. The ages ranged from 4 months to 22 years. In all instances but one, stenosis was of valvular type. As associated anomaly, atrial septal defect was detected in 2 instances (Table IV).

Table IV. Pulmonary Stenosis - A Total of 14 Cases

(up to Dec. 1963)

\begin{tabular}{|c|c|c|c|c|c|c|c|}
\hline 7 & Age & $0-2 \mathrm{yr}$ & $3-6 \mathrm{yr}$ & 7-10 yr. & $11-19 \mathrm{yr}$. & $20 \mathrm{yr}$. & Total \\
\hline \multirow{2}{*}{ 总寻㤩 } & PS & $1(1)$ & 1 & 2 & 5 & $1(1)$ & \multirow{2}{*}{$\begin{array}{l}10(2) \\
20 \%\end{array}$} \\
\hline & $\begin{array}{l}\text { Ass. } \\
\text { Ano. }\end{array}$ & ASD 1(1) & ASD 1 & & & Inf.S $1(1)$ & \\
\hline \multirow{2}{*}{ 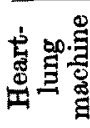 } & PS & & 2 & & 2 & & \multirow[t]{2}{*}{$4(0)$} \\
\hline & $\begin{array}{l}\text { Ass. } \\
\text { Ano. }\end{array}$ & & & C.Trans. 1 & & & \\
\hline
\end{tabular}

Four cases were operated upon by means of cardiopulmonary-bypass with no death, while 2 deaths were encountered among 10 operated with hypothermia (mortality: $20 \%$ ). The one of the deaths occurred in an infant with trilogy of Fallot, which was attributable to postoperative respiratory insufficiency. The other one was due to postoperative bleeding tednency in a patient with infundibular type of stenosis, which was mistaken for valvular type.

4) Tetralogy of Fallot. In the early period, less cyanotic patients were selected for operation, but operation was carried out even for markedly cyanotic patients, depending largely upon the desire of patients' families. In all instances heart-lung machine was used because of the necessity of prolonged circulatory interruption (more than 40 minutes). A total of 14 cases were operated upon with 7 deaths (mortality: 50\%) (Table V). In this series of patients, 1 was complicated by dextrocardia and 1 by persistent left superior vena cava, respectively. Two patients underwent Blalock's shunt operation several years ago. Because of aggravation of their symptoms, radical operation was undertaken. In 1, a shunt operation was planned, but during anesthesia cardiac arrest occurred, which was successfully resuscitated. Radical operation was successfully carried out 2 months 
Table V. Tetralogy of Fallot - A Total of 14 Cases

(up to Dec. 1963)

\begin{tabular}{|c|c|c|c|c|c|c|c|}
\hline \multicolumn{3}{|c|}{\begin{tabular}{l|l} 
Age & $0-2$ yr.
\end{tabular}} & 3-6 yr. & $7-10$ yr. & $11-19 \mathrm{yr}$. & $20 \mathrm{yr}$. & Total \\
\hline \multirow{3}{*}{ 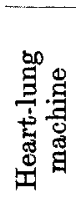 } & $\mathrm{T} / \mathrm{F}$ & & $3(1)$ & $5(3)$ & $5(2)$ & $1(1)$ & \multirow{3}{*}{$\begin{array}{c}14(7) \\
50 \%\end{array}$} \\
\hline & $\begin{array}{l}\text { Ass. } \\
\text { Ano. }\end{array}$ & & LSVC $1(1)$ & & D.card. 1(1) & & \\
\hline & Note & & & $\begin{array}{c}\text { Reoperation } \\
\mathbf{2}(1)\end{array}$ & $\begin{array}{c}\text { Reoperation } \\
\mathbf{1}(\mathbf{1})\end{array}$ & & \\
\hline
\end{tabular}

after this. One of these 5 patients was cured without complications, but the other 4 succumbed. The causes of deaths were right heart failure with pulmonary edema in 3 , postoperative hypotension in 2 , and cerebral embolism in 1 . In addition, one patient developed mediastinitis 1 week after operation with subsequent thrombosis of superior vena cava and eventually succumbed.

\section{COMMENT}

When we enumerate advantages and disadvantages of the use of hypothermia and heart-lung machine from our clinical experiences, hypothermia is simple in technique and postoperative management is not difficult. On the other hand, there exists a great restriction in the permissible time of circulatory interruption for open-heart operation. One occasionally encounters difficulty in resuscitation of the heart. In the extracorporeal circulation by means of heart-lung machine, there is less limitation of occlusion time, while the technique is more complicated with occasional appearance of postoperative bleeding tendency or fever. The current heart-lung machine is not adequate for infantile use in terms of unbalance of circulatory blood volume. Our policy for determination of indications of open-heart operations is to employ heart-lung machine for children of older age or adults who were considered to require intracardiac maneuver of more than 30 minutes' duration. For the cases who could be operated upon within a period of about 20 minutes or infantile cases in whom application of heartlung machine is not adequate ${ }^{6}$, hypothermia would be advisable. As to the types of diseases, for majority of ostium secundum defect, mild cases of ostium primum defect, all cases of infantile ventricular septal defect, mild cases of ventricular septal defect in children of older age and pulmonary stenosis, hypothermia is to be employed. On the other hand, the use of heart-lung machine would be indicated for the repair of severe cases of atrial septal defect and ventricular septal defect or other complicated anomalies such as tetralogy of Fallot.

In the early period, ventricular fibrillation tended to occur when the human body was cooled down to below $30^{\circ} \mathrm{C}$. This was the main reason for 
temporary abolishment of hypothermia in the past years. We have experienced a single instance with primary pulmonary hypertension in whom cardiac standstill and ventricular fibrillation occurred during the cooling process. Hypothermia is not a harmful procedure to humans, but it is safe when the patient is deeply anesthetized with ether and cooled down while ECG is in use as a monitor. Nevertheless, during the rewarming process, ventricular fibrillation tends to appear. Because of this, any unnecessary stimulation should be avoided. For example, previously, in the repair of atrial septal defect, in order to evacuate intraauricular air, saline solution was injected prior to approximation of the right atrial wall following closure of the defect. This maneuver occasionally caused cardiac standstill, since saline would drain into the coronary arteries after the release of the clamp. Cardiac massage at this time not infrequently produced ventricular fibrillation. No cardiac arrest, however, has been encountered since saline was replaced by heparinized blood. Furthermore, when the cardiac action was not active following unclamping, the electric pacemaker was applied to add direct stimuli to the myocard with successful resumption of strong cardiac action. When the circulatory interruption became prolonged, as a special device coronary perfusion was carried out with heparinized oxygenated blood following release of the occlusion. This could resuscitate the heart without cardiac massage. With these devices, ventricular fibrillation has become less likely to occur. Caution must be exercised against coronary air embolism or thromboembolism, since these phenomena would be a great obstacle to successful resuscitation of the heart. As to prevention of thrombus formation, $2 \mathrm{mg}$. of heparin was injected into the right auricle after occlusion of the inflow tracts prior to cardiotomy. After several pulsations were awaited, the aorta was clamped. In order to prevent air embolism, carbon dioxide insufflation to the operative field or needle puncture of the left ventricle for removal of air bubbles prior to unclamping would be of value.

In addition, the following several improvements have been made in an effort to obtain better operative results on the whole: (1) With regard to speed-up and rationalization of operative techniques, particularly for ventricular septal defect complicated by pulmonary hypertension, transverse incision was made over the right ventricular wall lest the right heart function should be disturbed postoperatively. In the closure of the defect with a Teflon patch, continuous suturing technique was employed, thus markedly shortening time of extracorporeal circulation. (2) About bleeding tendency following extracorporeal circulation, adequate heparin neutralization by calculating amount of heparin still remaining in blood, prophylaxis and/or treatment of hyperplasminemia with $\varepsilon$-aminocapronic acid, cortison and transfusion of fresh blood are important. (3) For the cases with pulmonary hypertension, a long-term administration of niamide recently advocated by Taguchi has undergone further investigation ${ }^{8)}$. The details on this matter are not to be described in the present paper. 


\section{References}

1) Swan, H., Zeavin, I., Blount, S.G. Jr. \& Virtue, R.W., J.A.M.A., 1953, 153, 1081.

2) Bigelow, W.G., Mustard, W.T. \& Evans, J.G., J. thorac. Surg., 1954, 28, 463.

3) Watanabe, A., Okamura, H., Takahashi, T., Toyoshima, J., Koyamada, K., Tomita, Y., Matano, I., Murakami, A. \& Horiuchi, T., Path. et Biol., 1959, 7, 1017.

4) Spohn, K., Kolb, E., Heizel, J. \& Kratzert, R., Langenbecks Arch. klin. Chir., 1959, $290,365$.

5) Spohn, K., Kolb, E., Heizel, J. \& Kratzert, R., Thoraxchirurgie, 1960, 8, 228.

6) Horiuchi, T., Koyamada, K., Matano, I., Mohri, H., Komatsu, T., Honda, T., Abe, T., Ishitoya, T., Sagawa, Y., Matsuzawa, K., Matsumura, M., Tsuda, T., Ishizawa, E., Ishikawa, S., Suzuki, H. \& Saito, Y., J. thorac. cardiovas. Surg., 1963, 46, 180.

7) Horiuchi, T., Koyamada, K., Matano, I., Mohri, H. \& Ishitoya, T., Jap. Circulation J., 1963, 27, 797.

8) Taguchi, K., Jap. J. thorac. Surg. (Jap.), 1962, 15, 496. 